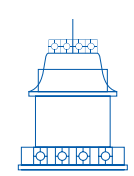

ARTÍCULO

DE REFLEXIÓN

\title{
The sense of mineness in personal memory: problems for the endorsement model*
}

\author{
Marina Trakas \\ Instituto de Investigaciones Filosóficas (IIF), SADAF/CONICET, Argentina \\ Email: marinatrakas@gmail.com
}

Recibido: 14 de mayo de 2021 | Aceptado: 3 de junio de 2021

https://doi.org/10.17533/udea.ef.n64a08

\begin{abstract}
What does it take for a subject to experience a personal memory as being her own? According to Fernández' (2019) model of endorsement, this particular phenomenal quality of our memories, their "sense of mineness", can be explained in terms of the experience of the mnemonic content as veridical. In this article, I criticize this model for two reasons: (a) the evidence that is used by Fernández to ground his theoretical proposal is dubious; and more importantly, (b) the endorsement model does not accommodate many non-pathological everyday memories that preserve their sense of mineness, but whose veridicality is explicitly denied, suspected, not automatically endorsed, or neither denied nor endorsed. Finally, I sketch two alternative explanations: one also problematic, the other one more promising, and present some normative advantages of the latter. This also displays the undesirability of the endorsement model from a normative perspective.
\end{abstract}

Keywords: personal memory, sense of mineness, sense of ownership, veridicality, nonbelieved memories

* This article is part of the research project "An epistemological and ethical inquiry into personal memories in context" founded by a postdoctoral scholarship granted by the Consejo Nacional de Investigaciones Científicas y Técnicas (CONICET), Argentina. I would like to thank Santiago Arango Muñoz and Chris McCarroll for their encouragement to send an article to this special issue and for their patience, and two anonymous reviewers for their comments and suggestions.

\section{Cómo citar este artículo}

Trakas, M. (2021). The sense of mineness in personal memory: problems for the endorsement model. Estudios de Filosofía, 64, 155-172. https://doi.org/10.17533/udea.ef.n64a08

\section{OPEN A ACCESS}




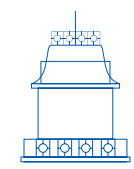

ARTÍCULO

DE REFLEXIÓN

\section{El sentido de mismidad de nuestros recuerdos personales: problemas del modelo de respaldo}

Resúmen: ¿Qué significa que un sujeto siente un recuerdo personal como propio? Según el modelo de respaldo de Fernández (2019), esta cualidad fenomenal particular de nuestros recuerdos, su "sentido de mismidad", se puede explicar en términos de la experiencia del contenido mnemónico como verídico. En este artículo, critico este modelo por dos razones: (a) la evidencia que utiliza Fernández para fundamentar su propuesta teórica es dudosa y, aún más importante, (b) dicho modelo no acomoda muchos recuerdos cotidianos no patológicos que preservan su sentido de mismidad, pero cuya veracidad es explícitamente negada, sospechada, no respaldada automáticamente, o ni denegada ni avalada. Finalmente, esbozo dos explicaciones alternativas: una también problemática, la otra más prometedora, y presento algunas ventajas normativas de la última, lo que a su vez muestra la indeseabilidad del modelo de respaldo desde una perspectiva normativa.

Palabras clave: memoria personal, sentido de mismidad, sentido de posesión, veracidad, recuerdos no-creídos

\section{Marina Trakas}

PhD in Philosophy (Macquarie University, Australia); PhD in Cognitive Science (Institut Jean Nicod, France); Postdoctoral researcher, Consejo Nacional de Investigaciones Científicas y Tecnológicas (CONICET), Argentina. Member of the Instituto de Investigaciones Filosóficas (IIF), Sociedad Argentina de Análisis Filosófico / CONICET.

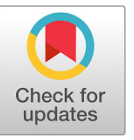


When we remember a past personal experience, we are not only aware of the fact that a certain type of mental phenomenon is being instantiated, in this case a personal memory, but we are also aware of the memory as being our own. These are in principle two different feelings. A hypothetical creature to whom we may transfer our personal memories could certainly have the sense that a memory is being presented to her, without experiencing that these are her memories, that what is presented to her are her past experiences. In our everyday mental life, the first kind of feeling is common to all mental phenomena, i.e., all non-pathological mental phenomena are presented as occurring in our minds; whereas the second feeling seems to be particular to personal memory experiences. We feel our personal memories as our own in a non-trivial essential way: they belong to us in a way in which they could not belong to someone other than us. They refer to our own past, to our previous experiences, and not to the past and experiences of someone else; that is why we attribute our memories to ourselves.

In this article, I focus on this particular sense in which personal memories are felt as our own, and analyse the specific conceptualization of this feeling recently developed by Fernández (2019). My aim here is relatively simple: I show that the "endorsement model" proposed by Fernández (2019) to account for this particular feeling does not offer a good explanation of the phenomenon it intends to explain. For this purpose, I briefly characterize the endorsement model and then explain in detail the problems that this model faces. I argue, first, that the endorsement model is not firmly grounded on the empirical evidence presented by Fernández, as he claims; and second, and more importantly, that it cannot account for the sense of mineness of a group of non-pathological everyday memories which are not endorsed by the rememberer. I use the term "sense of mineness" to refer to the explanandum of the model. Fernández is sometimes ambiguous about the terminology and indistinctly uses "sense of mineness" and "sense of ownership". I simplify the discussion by using a single term, without necessarily taking a stance about its suitability in comparison with other similar terms appearing in the literature. ${ }^{1}$ After the analysis of Fernández' endorsement model of the sense of mineness of our personal memories, I introduce an alternative version of the endorsement model which nonetheless presents some similarities with Fernández' proposal. I show that this more modest version of the endorsement model is also problematic, and that a better explanation of the sense of mineness of our personal memories may emerge from an improved and more detailed version of the "identification model". I finally sketch some normative advantages of the latter option, which at the same time show the undesirability from a normative perspective of the endorsement model and its assumptions about the nature of memory.

1 In fact, in the current literature about mental states (and not, in particular, about memory), the terminology to refer to the general feeling of presence of a mental state in our consciousness is quite messy: sense of ownership, sense of autorship, (sense of) mineness, for-me-ness, felt mineness, etc. (see, for example, Gerrans, 2001; Salje \& Geddes, forthcoming). 


\section{The endorsement model}

The endorsement model of the sense of mineness is defended by Fernández (2019). According to his model, the sense of mineness of our memories, that is, the experience of a memory as being the subject's own, is the experience of the memory as matching the past. When a subject remembers, she feels that the remembered action or experience did take place in the past, so she endorses her memory and experiences it as being her own, that is, as having a sense of mineness: "the feeling of a memory as being one's own and the sense that the memory is matching the past are one and the same experience" (Fernández, 2019, p. 123).

This equation is possible because when the subject feels that a remembered scene has been experienced by her, she actually experiences one of the things represented by her memory: the fact that the memory has been caused by her having a perception (Fernández, 2019, p. 125). In fact, Fernández defends a reflexive view of memory: memory not only represents a past perceptual experience of the subject as having caused the memory, but it also represents that perceptual experience as having been veridical, so as a past perception, and not, let's say, as a past illusion or hallucination. It does not matter if the past perceptual experience was actually veridical or not; it matters how memory represents it, and according to Fernández memory represents it as being veridical. So memory represents its own causal history by representing itself as originating in a past perception. The experience of this specific causal origin is the experience of the sense of mineness. Note that the experience of the causality of the memory includes the experience of its veridicality: by representing its causal origin in a past perception and not simply in a past experience, a memory represents itself as being veridical, as matching the past. Fernández embeds the sense of mineness in the content of memory, and in this way grounds the phenomenology of memory in its intentionality, as he originally intended (Fernández, 2019, p. 23).

Therefore, within this framework, a memory that lacks a sense of mineness, a "disowned memory", is a memory whose content has been disrupted. The memory no longer represents itself as originating in a past perception; it represents itself as originating in a past perceptual experience, but this past perceptual experience is not represented as having been veridical. So the subject believes that she is remembering a scene, but she does not feel like she is remembering that scene, because she does not have the feeling that the scene represented in those memories happened in the past. Nonetheless, a disowned memory can still be recognized as a memory by the rememberer, because the content of disowned memories is sufficiently similar to the one of a typical memory. A disowned memory still represents part of its causal origin: that it has been originated in a past perceptual experience. So someone who disowns a memory may still refer to her mental state as memory and not as an 
episode of imagination. The content of disowned memories is disrupted (Fernández, 2019, p. 125), but it is still "mnemonic" in nature because it is still reflexive.

\section{Problems for the endorsement model}

Fernández' proposal is attractive because of the coherence between the endorsement model of the sense of mineness and his theory of memory content. Despite this, it presents many shortcomings that make it an unsatisfactory account of the sense of mineness.

Fernández bases his whole theoretical analysis of the sense of mineness in the linguistic analysis of some reports of the patient R.B., investigated by Klein \& Nichols (2012). R.B. is a subject who, after an accident, seemed to suffer a specific memory problem for some time: he claimed to have memories but at the same time to not feel these memories as his own. Fernández' model of sense of mineness as endorsement is presented as the best model that accommodates R.B.'s case. So it intends then to be an empirically grounded model that offers the best explanation of the sense of mineness of our memories. Nonetheless, Fernández' endorsement model is inadequate to explain the phenomenon it intends to explain, and this for many reasons.

First, there is no reason to believe that the endorsement model is the best model that accommodates R.B.'s case. Fernández bases his theoretical conclusions on the analysis of only some of R.B.'s reports cited in the literature (Fernández, 2019, p. 114). An account solely based on R.B. reports should provide an exhaustive and detailed analysis of all the available reports. But this is not Fernández' strategy, who deliberately omits those reports that he considers to be neutral for his analysis, but that may, in fact, not be neutral. Two reports omitted are of particular interest for his argumentation (Stanley \& Klein, 2012, p. 685; p. 688): ${ }^{2}$ both of them mention that R.B. did not feel as if he was the same person who performed or experienced something in the past. This kind of description of the phenomenon would give more support to the explanation given by Klein and Nichols (2012) and rejected by Fernández: the sense of mineness refers to the sense of numerical identity with the past person (which is known as "the identifi-cation model": Fernández, 2019, pp. 117-119). On the other hand, it would be difficult to interpret these descriptions according to the framework proposed by the

2 "I could answer any question about where I lived at different times in my life, who my friends were, where I went to school, activities I enjoyed, etc. But none of it was 'me'. It was the same sort of knowledge I might have about how my parents met or the history of the Civil War or something like that" (Klein \& Nichols, 2012, p. 685). "I didn't feel 'down' about not being able to walk, etc. Because it was as if I was learning to walk for the first time. There was no sense of loss. Only a sense of gaining new skills and meeting these interesting new challenges. I knew that I once could walk, but it wasn't 'me' who once could walk" (Klein \& Nichols, 2012, p. 688). 
endorsement model. Fernández should have considered all R.B.'s verbal reports publicly available if he intended to use them in order to weigh one model against the other.

Second, it is doubtful that a good account of our sense of mineness is an account that accommodates R.B.'s case. It is not really a problem that R.B. is the single case worldwide reported with this specific pathology. ${ }^{3}$ Many major contributions to cognitive science come from the study of single cases (Rosembaum, Gilboa \& Moscovitch, 2014). The real problem is that there is not robust data on R.B. 's case, so it cannot be taken as a solid empirical ground from which to build a theory to explain memory phenomena. The loss of R.B.'s memories' sense of mineness was temporary (Klein \& Nichols, 2012, p. 688), and he was only interviewed by these researchers. In fact, only a few fragments of the interviews are offered by the authors with the aim of defending more philosophical than empirical claims about the nature of personal identity, autonoesis, and episodic memory (Klein \& Nichols, 2012; Klein, 2013; 2014; 2015), and at least one of these reports is not cited consistently in different publications. ${ }^{4}$ Furthermore, Klein and Nichols mention verbal fluency and short-term memory tests performed on R.B. (Klein \& Nichols, 2012, p. 684), but it does not seem that R.B. has been subject to exhaustive formal testing. R.B.'s case is blurred in so many ways that it is better to not count on it as solid evidence, or to take it with extreme caution.

Because of these two previous reasons, it is better to ignore the endorsement model's grounds on R.B.'s reports and to analyse it as a theoretical proposal that is not empirically grounded. This means that the equation between sense of mineness and memory endorsement needs to be tested with real life memories, in order to see if it is sufficiently explanatory or not. Two moves are possible for this purpose: a more analytical move and an empirically oriented move. As I show next, both of them finally meet and support the same conclusion, that is, that the endorsement model does not constitute a good account of the sense of mineness of our personal memories.

3 The two other historical cases invoked by Klein and Nichols that are supposed to be quite similar to R. B. are not really alike. Unlike R. B., both patients are amnesic. From the short description given by Talland (1964), his patient seems to present short-term memory deficits and source amnesia: after recalling some past personal events, he believed that the interviewer was the original source of the information that in fact he had given himself. J.V., the patient studied by Stuss and Guzman (1988), presents retrograde amnesia, especially for events personally experienced. He had nonetheless relearned some of his own past experiences through conversations and photographs, and he was aware in many cases of the real source of his "new memories". Because of this origin, these relearned events were recalled as if they were semantic information, and that is why "he has no feeling of personal warmth, intimacy, or belonging that the memory is his, or that he was somehow involved" (Stuss \& Guzman, p. 27).

4 Compare "I can see the scene in my head. I'm studying with friends in the lounge at my residence hall. I am able to re-live it. I have a feeling [...] a sense of being at there, at MIT, in the lounge. But it doesn't feel like I own it. It's like I'm imagining, re-living the experience but it was described by someone else" (Klein \& Nichols, 2012, p. 687), with "I can see the scene in my head [...] I'm studying with friends in the lounge in the residence hall. But it doesn't feel like its mine [...] that I own it. It's like imagining the experience, but it was described by someone else" (Klein, 2015, p. 18). In this second quote, there is no mention of "re-living". 
The first move consists in finding a counterexample, and this is quite easy: we only have to look in our memory repertoire. Until I was more or less 20, I had two or three extremely vivid memories of my childhood that I still used to experience as being my own, as having a strong sense of mineness, but without endorsing their accuracy. Today they have lost their strong experiential character, as it has probably happened to all the memories from my childhood; but until my twenties these specific non-endorsed memories were extremely vivid and felt like real ones. One of them referred to a dinner at home with Enrique Discépolo, a famous tango composer. I used to remember him having dinner in our dinner room, with me and my parents. He was sitting in a particular chair near a corner, around an old dining table that we used to have when I was a young child, dining with my parents as if they were very close friends. When I was old enough, and after asking many times about this, my parents made me understand that this scene did not take place. Unfortunately, not only did my parents not personally know Discépolo, but Discépolo had died decades before my birth. So the event I remembered was not even remotely possible. Nonetheless, for a long time until my twenties, this past scene was so vivid and full of details, that I still experienced it as being my own, in a similar way I experienced the mineness of truly accurate memories. But because I knew this event was not real, I did not endorse the memory. I felt that I was remembering without feeling nor believing that the remembered experience did take place in the past and was veridical. But I still had the feeling that this scene belonged to my personal past in a non-trivial way and was my memory. This feeling could not possibly come from my experience of the fact that this memory has been caused by me having a perception. My memory did not anymore represent my past perceptual experience as having been veridical, so I could not possibly experience what was not represented in my memory, yet I still experienced a sense of mineness.

My Discépolo memory constitutes a good counterexample to Fernández' model of sense of mineness as endorsement. According to Fernández' framework, the content of my Discépolo memory would be disrupted: the memory does not represent itself as being caused by a past perception, so it does not represent itself as being veridical; but it still presents a sense of mineness. Therefore, the disruption or not of this particular memory content, and its consequent experience, does not seem to be related to the presence or absence of the sense of mineness.

My Discépolo memory provides evidence against the endorsement model proposed by Fernández. But this counterexample alone has no more value than R. B.'s reports, which Fernández considers to be supportive of his thesis. Nonetheless, it turns out that my Discépolo memory is not an isolated case, and that these cases are not rare phenomena. The psychologists Alan Scoboria and Giuliana Mazzoni have largely studied these kinds of memories of events that are no longer believed, which are called "nonbelieved memories". According to the first study on non-believed memories (Mazzoni, Scoboria \& Harvey, 2010), more than $20 \%$ of participants reported a non-believed memory from a poll of more than 1500 students. Another more recent study, which 
analysed "humorous, obscure and uncomfortable" false memories that have been spontaneously submitted by people for an art project, found that more than a half of those false memories were non-believed memories (Otgaar, Bücken, Bogaard,Wade, Hopwood, Scoboria \& Howe, 2019). In fact, nonbelieved memories need not be false memories; true memories can also be non-believed, especially due to social influence (Mazzoni, Clark \& Nash, 2014) So non-believed memories are quite common. Nonbelieved memories are autobiographical recollections that exist without accompanying autobiographical belief, or belief in the occurrence of the event remembered. Despite the withdrawal of belief, non-believed memories are still experienced as memories and not, for example, as imaginative acts, because they present very high ratings of memory-like qualities. Non-believed and believed memories show similar ratings of reliving, mental time travel, vividness of details, perceptual visual and tactile characteristics, intensity of feeling, richness of emotional content, and clarity of the location and spatial arrangements of objects and people in the event (Mazzoni et al, 2010). It is true that none of these characteristics correspond to the "sense of mineness" understood in a philosophical sense. But it is clear from all these characteristics that during recollection of non-believed memories, the rememberer is aware of the scene as having been experienced by her in the past. If she was not aware of the scene as having been experienced by her in the past, her current experience would not be taken to be a personal memory experience, so it would not present high ratings of reliving, mental time travel, vividness and clarity of details and elements. Although we may disagree about the necessity of all these traits for an experience to be a personal memory (some memories may not entail mentally travelling back in time, or may be poor in details), there is agreement that the presence of these traits signals a memory experience. Sufficient levels of vivid perceptual imagery, emotional content and a sense of re-experiencing the past generally lead the rememberer to label her mental representations as memories (Rubin, Schrauf \& Greeberg, 2003). We may also disagree about the precise nature of the sense of mineness, but there is also agreement that the sense of mineness is a constitutive part of what a personal memory experience is. This point is nicely illustrated by Sacks (2005), who suggests that different phenomenal characteristics of our personal memories, including the sense of mineness, are deeply intertwined. In his retelling of the acknowledgement that a memory of his childhood was false, he states to not having found any phenomenal difference between a true and believed memory and his now false and nonbelieved memory: this latter, he tells us, "was equally clear, it seemed to me -very vivid, detailed, and concrete (...) it still seems to me as real, as intensely my own, as before" (p. 11). It is thus undeniable then that non-believed memories, like any kind of memory, present a sense of mineness. As Mazzoni, Scoboria, \& Harvey (2010) explain, "there is no need to believe in the occurrence of an event to still 'feel' the memory as a compelling experience" (p. 12). Memories can be non-believed, that is, they can lack the veridicality postulated by the endorsement model, but still feel as 
something that has been somehow previously experienced by me, as something so "strongly embedded in my psyche" (Sacks, 2005) and in my personal past that they cannot be phenomenally distinguished from believed memories.

It is also true that believed memories present greater personal significance and connectedness to other life events than non-believed memories, making non-believed memories less "connected to the self" than their counterpart (Mazzoni, et al., 2010, p. 13). But this does not undermine their sense of mineness. And if their sense of mineness is considered to be diminished because of this lack of connectedness, this diminished sense of mineness could not be taken as distinctive of non-believed memories. There are many believed memories which, for different reasons, could also be considered to be poorly connected to other past events or to the self. "Free radicals", that is, memories of events that have not become integrated with autobiographical knowledge (Conway, 2009), memories of specific past shameful acts remembered after a radical change in one's traits and values (Goldie, 2012), could both be considered to present a diminished sense of mineness understood in this sense. Nonetheless, there is no reason to consider the sense of mineness of a memory as equivalent to the experience of its connectedness and coherence with the self and other memories. Although this factor could influence the sense of mineness in a qualitative manner, it determines neither the absence nor the presence of the sense of mineness, as the phenomenology of some non-believed memories (such as my Discépolo memory, which was neither coherent nor possible) and of free radicals show. Absence of coherence with the self or other memories does not prevent the rememberer from feeling the past event recalled as having been experienced by her.

In consequence, it seems that Fernández' endorsement model of the sense of mineness does not pass the test: it is not sufficiently explanatory. The existence of nonbelieved memories leads us to the third and decisive point against it: the endorsement model does not accommodate some non-pathological everyday memories whose veridicality is explicitly denied but which still present a sense of mineness.

An advocate of the endorsement model proposed by Fernández could nevertheless raise an objection. Non-believed memories are still experienced as memories because in the past they actually represented themselves as originating in past perceptions and formerly held a high belief value. So the persistence of the sense of mineness can be explained in terms of the original content of the memory, which represented itself as being veridical. Although this content has changed, i.e., it does not represent anymore as originating in a past perception and being veridical, the sense of mineness of the memory still persists as a residual condition of the experience of this original content. According to this view, the endorsement model would account for the sense of mineness of non-believed memories; that is why it would be sufficiently explanatory for this phenomenon.

This line of argument is nevertheless problematic. It assumes that memories always intrinsically represent themselves as originating in past perceptions, 
and so, that recollecting an event and believing that the event occurred happen simultaneously because they are either both part of the same experience, or at least strongly correlated. The functionalist theory of memory proposed by Fernández explicitly states this point: "For any subject $\mathrm{S}$ and proposition $\mathrm{p}$, S remembers that $\mathrm{p}$ just in case $\mathrm{S}$ has some mental image $\mathrm{i}$ such that $\mathrm{i}$ tends to cause in $\mathrm{S}$ a disposition to believe both that $p$ and that $S$ experienced that $p$, and i tends to be caused in S by having experienced that p" (Fernández, 2019, p. 49). Tulving had also informally suggested the same idea: "the feeling that the present recollective experience refers to a past event, and the feeling that the experience is veridical, that it represents the past faithfully, are given as an integral part of the subjective experience of remembering" (Tulving, 1983, p. 187). But recent empirical research shows otherwise. Although prior research was inclined to analyse memories and autobiographical beliefs as partially dissociated but generally correlated (Scoboria, Mazzoni, Kirsch \& Relya, 2004), new research using Confirmatory Factor Analysis ${ }^{5}$ supports the idea that they are better conceived as strongly independent of each other (Scoboria, Jackson, Talarico, Hanczakowski, Wysman \& Mazzoni, 2014). Memories and autobiographical beliefs, that is, beliefs in the occurrence of the event remembered, represent two distinct continuous variables that can manifest in different combinations across mental events. At the extreme of these possible combinations, there are four "pure" event types: "believed memories", "non-believed memories", "believed-not-remembered" and "not-believed-not-remembered". Whereas the first two refer to memory experiences and the third to autobiographical beliefs about personal events that are not remembered, the fourth refers to past personal events that may or may not have happened, but are neither believed nor remembered. This means that our everyday memories scatter across the two extremes: "nonbelieved memories" and "believed memories". Believed memories are certainly more common than non-believed memories, but between these two extremes there are many memories high in recollection for which the belief in the event remembered has been brought into question but not substantially undermined. These "grain-ofdoubt" memories (Scoboria, Nash \& Mazzoni, 2016) ${ }^{6}$ occur frequently and, if the

5 Confirmatory Factor analysis (CFA) is an analysis tool that helps the researcher to test the fit of data to a previously specified model, and thus bridge the gap between observation and theory. As Scorobia \& et al. (2014) explain, "the researcher defines in advance what factors will be present and onto which specific factor(s) items will load. The data are then used to evaluate the extent to which the model explains covariance amongst the measured variables, resulting in an estimate of the degree to which the proposed theoretical model represents a good fit to the data" (p. 1246). Whereas a model with different items loading on a single factor (memory = belief) did not fit the data well, a two factor model (memory and belief) was a good fit of the data. The same procedure was used to assess the data-model fit of the different event types mentioned below in the main text.

6 Scoboria, et al., (2016) have in fact called these memories "grain-of-doubt" non-believed memories when analyzing the different types of non-believed memories. I think nevertheless that it would be better suited with their previous work (Scoboria, et al., 2014) to talk about "grain-of-doubt" memories tout court; technically, these memories are not "non-believed", but "suspected" or "dubious". 
need to know their truth value arises, this need is generally resolved by turning to social resources for assistance, such as external evidence and testimony. So "grainof-doubt" memories are another good example of an explicit dissociation between memory and autobiographical belief.

Furthermore, this dissociation is also observed between the predictors of the variables (Scorobia \& et al., 2014). Whereas rich visual imagery, the feeling of reexperiencing, emotion intensity, and event specificity are good predictors of recollection but do not predict belief, general event plausibility and personal plausibility predict autobiographical belief strongly and recollection only weakly. In fact, autobiographical beliefs seem to be influenced by multiple sources of information and processes, such as factual knowledge, inferential processes and, particularly, by the acquisition of socially transmitted information and social influence (Scoboria, Boucher \& Mazzoni, 2015). Recollection is only one among many factors that influence autobiographical belief, and it is not even a necessary one. As Scorobia et al., (2014) have stated, "the processes that impact recollection tend to be internal and cognitive/memorial in nature", whereas "the processes that impact autobiographical belief originate in both internal and external experience and are strongly socially mediated" (p. 1255). Even the metacognitive processes that govern the endorsement of an event as occurred differ from the metacognitive processes that govern the endorsement of an event as remembered. The conclusion that one remembers an event depends on the interaction between the qualities of the "raw output" of memory retrieval processes (vividness, fluency, etc) and the implicit criterion for judging that mental content as a memory. On the other hand, the metacognitive processes that determine the likelihood that a personal event happened can be based on information that the rememberer already has - which can but need not be the memory of the event in question- and on newly provided information (Mazzoni \& Kirsch, 2002). Certain metacognitive feelings, such as the feeling of rightness, confidence, error or uncertainty, play a crucial role in motivating (or not) the subject to resort to social sources (Arango-Muñoz, 2013). When people turn to social sources, they can (a) endorse the new information; (b) reject the new information; (c) seek additional information; (d) diminish the importance of the event, especially when motivations to maintain close and meaningful relationships override motivations to be accurate (Scorobia et al., 2014). While in cases (a) and (b) an autobiographical belief is formed or changed, in case (c) the subject remains in a state of doubt and inquiry, and in case (d) the belief or not in the occurrence of the event is withheld or suspended (the subject neither believes nor disbelieves the occurrence of the event). ${ }^{7}$ In all four cases, nonetheless, a memory of the event in question may be present and persist.

7 For the notion of "suspended judgement" as a genuine third option between belief and disbelief, see, for example, Friedman (2013): "Suspending then is (other things equal) a way of (at least temporarily) terminating a deliberative process that is sufficient for getting into a state of agnosticism" (p. 179). 
Therefore, non-believed memories, mainly of episodes of our childhood, are not the only case where the dissociation and independence between memory and belief is undeniable. Grain-of-doubt memories and "suspended-belief" memories are very common phenomena that happen in everyday life, for example, when we vividly visualize ourselves locking the front door of our house, but we are not really sure if we did it, so we go back to check that the door is locked indeed. Or when we clearly remember telling our partner to buy bananas, but she claims we did not, and in order to avoid a fight we simply say "ok, it does not matter", implicitly suspending our belief or disbelief in our past request even though it is still remembered. What is more, Blank (2016) mentions other memory phenomena where the divergence between memory and belief is also evident: the déjà vu phenomenon (feeling of recollection + a strong awareness of inaccuracy); some cases of misinformation effect (feeling of recollection of an event + belief in a different event due to the information presented later); some memories of childhood sexual abuse (no memory of abuse + belief in abuse; or memory abuse + disbelief in abuse); stereotype-induced memory distortion (vague and ambiguous memories + belief formed due to stereotypes). The independence of these two constructs, memory and belief, does not mean that they do not influence each other, although more studies are needed in order to better specify the nature of this interaction. ${ }^{8}$

In conclusion, the possible objection of the advocate of the endorsement model previously mentioned does not work. The sense of mineness of non-believed memories cannot be explained in terms of the persistence of the experience of a supposed original -but lost-mnemic content that represented itself as originating in a past perception and being veridical. Recent empirical evidence points to a different direction: the sense of mineness, which is intrinsically tied to the recollective experience, is a different construct from the degree of belief attached to a past remembered experience. Experiences remembered do not necessarily represent themselves as having been veridical in the past, as having been a past perception. At most, they represent themselves as having been somehow experienced me, the rememberer. But memories do not come with an intrinsic label that says "veridical experience" and that makes us feel that they were veridical; this label is ascribed to the past experience through different processes and evidence that are not necessarily mnemonic in nature.

8 Mazzoni \& Kirsch (2002) suggest that, besides the repetition of the content, a belief may also create a false memory by affecting the person's criterion for judging the mental content to be a memory: "the more likely the event is to have happened, the easier it is to conclude that a corresponding mental content is a memory, rather than merely a fantasy, imagining, etc." (p. 140). Recently, it has been suggested that false memories can be reversed through different techniques that ultimately change the belief of the subject (Oeberst, Wachendörfer, Imhoff \& Blank, 2021). Nonetheless, Hyman (2021) is sceptical about this prospect. According to him, what Oeberst et al. have shown is that the belief in the memory has been reversed but not the memory itself: "The memory remains. We may no longer believe the memory is true. But the memory remains. We can erase the belief in the memory. But the images and the stories may stay in memory" (para. 16). 
The third and decisive point against Fernández' endorsement model can thus be reformulated in the following terms: the endorsement model is not sufficiently explanatory because it does not accommodate many non-pathological everyday memories that preserve their sense of mineness, but whose veridicality is explicitly denied, suspected, not automatically endorsed, or neither denied nor endorsed. Furthermore, the previous analysis shows another weakness of Fernández' proposal: the idea that the memory content represents itself as being veridical. The veridicality of a memory is a property that the memory may acquire when the event remembered is judged to have occurred. It is thus not internal to the content of the memory, but attributed after memory retrieval, through processes that are not necessarily mnemonic. So this not only rules out epistemic theories of memory, which equate memory to knowledge or belief, but also challenges Fernández' functionalism: although it is certainly true that many memories tend to cause in us a disposition to believe in the occurrence of the event remembered, the memory status of a mental state cannot be defined in terms of this disposition. Some memories do not produce a tendency to believe in their content.

\section{Future research directions}

All these previous considerations show that the endorsement model of the sense of mineness proposed by Fernández (2019) is not a good model of the phenomenon it intends to explain:

(a) There is no reason to believe that it is the best model of the sense of mineness that accommodates R. B.'s case;

(b) It is doubtful that a good account of our sense of mineness is an account that accommodates R. B.'s case;

(c) It does not accommodate many non-pathological everyday memories that preserve their sense of mineness, but whose veridicality is explicitly denied, suspected, not automatically endorsed, or neither denied nor endorsed.

The unsatisfactory explanatory power attributable to the endorsement model of the sense of mineness opens up different possibilities. On one hand, the sense of mineness of memories could still be conceived as the experience of the memory content; but this would entail a redefinition of the memory content. The memory content as it has been conceptualized by Fernández cannot explain the sense of mineness -and additionally, it does not seem to be a good conceptualization of the memory content. This move may nevertheless be tricky: it may demand the memory content to do "too much" explanatory work, especially when considering that memory is sometimes used for non mnemonic purposes, such as imaginative purposes. But this move still may be worth trying if the memory content is not considered as the simple activation 
of memory traces (which can be used for non mnemonic purposes), but as the final output resulting from retrieval memory processes. Therefore, a more modest model of endorsement could be proposed to explain the sense of mineness. In this version of the model of endorsement, the experience of the sense of mineness still corresponds to the experience of the causal origin of our memories that is given in the memory content. But the memory content represents itself as originating in a past perceptual experience, not in a past perception, so it does not represent itself as being veridical. The memory content is still reflexive, that is, it represents its own causal origin, but it is neutral about the veridicality of the past experience that caused it. This more modest model of endorsement that is grounded on a more modest model of the reflexive nature of memory could still accommodate the sense of mineness. The sense of mineness would correspond then to the awareness of the scene remembered as having been experienced in the past. So in this moderate model of the sense of mineness as endorsement, what is endorsed is not the veridicality of the memory content, but simply the existence of a previous experience (perception, illusion, hallucination, dream, imagination, etc.) where the memory originated.

Nonetheless, this moderate model of endorsement may not be a good explanation of the sense of mineness. Consider again my Discépolo memory. I probably discovered Discépolo through a book in our library, which presented hand-made portraits of different tango composers together with their biography and the lyrics of one of their songs. Maybe then I dreamt about a dinner with Discépolo at home, but I am not really sure if my memory was due to a source monitoring error. Maybe there was no dream, no previous hallucination or other experience from which my memory originated, and my memory was the result of anomalous processing of different elements: my memory of the hand-made portrait of Discépolo, my parents listening to tango, my eagerness (?) to receive a celebrity at home, etc. The truth is that I do not have any idea about the kind of experience, if there was such experience, that engendered my Discépolo memory. So, although not technically impossible, it is suspicious to ground the sense of mineness in the awareness of the scene remembered as having been caused by a previous indeterminate, unspecified -and maybe non-existent-experience in the past.

In Fernández' model of endorsement as well as in this more modest proposal, the weight of the causal origin is put on the side of the object, i.e., the past event or experience, and not on the side of the subject. Although the experience is not always there, like in my Discépolo memory, the subject always is, and focusing on this aspect of the memory may be a more promising line of inquiry to explain the nature of the sense of mineness. Why do I feel particular mental states as my memories? Because they (re) present themselves as originating in my past self, who is the same as me. The idea that the sense of mineness refers to the sense of numerical personal identity with the past person was the original thesis proposed by Klein \& Nichols (2012) to explain R. B.'s case, which was nevertheless rejected by Fernández for not being a good explanation of R. B.'s reports. It deserves nonetheless to be better explored, considering that there 
are some unclear aspects that need further elaboration. To name just a few: it is not evident that the notion of identification with the past self properly captures the nature of the sense of mineness. The notion of identification implies a two-step process, or an inferential process that does not seem to be part of the experience of the sense of mineness, which is given immediately and non-inferentially. ${ }^{9}$ But abandoning the notion of identification leaves an explanatory void that needs to be fulfilled with some other concept or explanation. On the other hand, another aspect that needs clarification refers to the "mental location" of the past self. Either the past self is -implicitly or explicitly- represented in the content of the memory, so the memory represents itself as originating in the past self and the sense of mineness arises from the experience of this content; or the past self is not represented in the content. In the latter case, the memory presents itself as originating in my past self, but this causal origin and the identification or "sameness" between present self and past self are not part of the memory content. They may be the phenomenal flip side of subpersonal and automatic metacognitive memory processes. In this framework, the sense of mineness of memories could be then conceived as a metacognitive feeling. This is probably a more viable option than assuming that the sense of mineness originates in the experience of the memory content itself, and a promising line of research that deserves further development.

\section{Desirability of the endorsement model?}

To conclude, I would like to briefly present some advantages of the ideas sketched in the previous section in order to explain the nature of the sense of mineness of our personal memories. These advantages show, at the same time, that Fernández' endorsement model of the sense of mineness as well as its assumptions about the nature of the memory content are not a desirable account of memory from a normative perspective.

First, when memory is conceived as different from belief or from a tendency to produce a belief, the rememberer understands that some beliefs she may have about past events personally experienced may have been formed from sources different from memory itself. This kind of understanding turns out to be useful in many settings in which what matters is the original memory, such as in forensic contexts. For example, a subject may believe that she saw a person $\mathrm{X}$ stealing a car, but in fact this may be a belief she formed from many sources different from the original memory: her previous knowledge of X's reputation as a thief and X usually wearing a cap; a neighbor telling her that he saw $X$ that morning walking around the neighborhood in a suspicious way; a neighbor asserting that it must be $\mathrm{X}$ who stole

9 A similar criticism has been raised by McCarroll (2018) in his account of the way one sees oneself in visual observer memories. 
the car. The only thing that she may actually remember is that she saw a silhouette of a man with a cap stealing the car.

Second, when memory is understood as not being necessarily veridical, the rememberer can pay more attention to her metacognitive feelings (especially feelings of uncertainty and error) and can be more motivated to resort to external and social sources if her memory is considered to be doubtful. A healthy dose of doubt triggers further inquiry and improves the chances of forming a better representation of the past. These kinds of epistemic actions can also be triggered by the understanding that in many circumstances memory does not present to us objective facts but subjective personal perspectives of what happened, and that other perspectives may be needed to better grasp the past. This kind of understanding may be particularly useful when remembering experiences that are important for interpersonal relationships. For example, if my partner remembers that I have been treating him with disdain but I do not, I may consider that my memory only presents to me my subjective perspective of the past, and that my partner's perspective may be not only a different perspective but also a valid perspective that needs my full consideration in order to get a complete picture of my past interactions with him (Trakas, 2019). Therefore, a sense of mineness understood as focused on the side of the subject ("it was me who experienced some event") may be more epistemically beneficial than a sense of mineness understood as focused on the side of the object ("this event happened" or "this experience took place"). The understanding of the subjective side of memories may help the subject to avoid or overcome self-deception, and to adopt certain kinds of attitudes such as being open-minded and responsive to others' memories, all of which is essential to become a more epistemically responsible rememberer.

\section{References:}

Arango-Muñoz, S. (2013). Scaffolded memory and metacognitive feelings. Review of Philosophy and Psychology, 4(1), 135-152. https://doi.org/10.1007/s13164-012-0124-1

Conway, M. A. (2009). Episodic memories. Neuropsychologia, 47(11), 2305-2313. https://doi. org/10.1016/j.neuropsychologia.2009.02.003

Fernández, J. (2019). Memory: a self-referential account. Oxford University Press. https://doi. org/10.1093/oso/9780190073008.001.0001

Friedman, J. (2013). Suspended judgment. Philosophical studies, 162(2), 165-181. https://doi. org/10.1007/s11098-011-9753-y

Hyman, I. (2021, May). Can we erase false memories? Psychology Today. https://www. psychologytoday.com/us/blog/mental-mishaps/202105/can-we-erase-false-memories

Gerrans, P. (2001). Authorship and ownership of thoughts. Philosophy, Psychiatry, \& Psychology, 8(2), 231-237. https://doi.org/10.1353/ppp.2001.0009 
Goldie, P. (2012). The mess inside: narrative, emotion and the mind. Oxford University Press. https://doi.org/10.1093/acprof:0so/9780199230730.001.0001

Klein, S. B. \& Nichols, S. (2012). Memory and the sense of personal identity. Mind, 121, 677-702. https://doi.org/10.1093/mind/fzs080

Klein, S. B. (2013). Making the case that episodic recollection is attributable to operations occurring at retrieval rather than to content stored in a dedicated subsystem of longterm memory. Frontiers in Behavioral Neuroscience, 7, 3. https://doi.org/10.3389/ fnbeh.2013.00003

Klein, S. B. (2014). Autonoesis and belief in a personal past: an evolutionary theory of episodic memory indices. Review of Philosophy and Psychology, 5(3), 427-447. https://doi. org/10.1007/s13164-014-0181-8

Klein, S. B. (2015). What memory is. Wiley Interdisciplinary Reviews: Cognitive Science, 6(1), 1-38. https://doi.org/10.1002/wcs.1333

Mazzoni, G. A. L., Clark, A. \& Nash, R. A. (2014). Disowned recollections: denying true experiences undermines belief in occurrence but not judgments of remembering. Acta Psychologica, 145, 139-146. https://doi.org/10.1016/j.actpsy.2013.11.007

Mazzoni, G. A. L., Scoboria, A. \& Harvey, L. (2010). Non-believed memories. Psychological Science, 21, 1334-1340. https://doi.org/10.1177/0956797610379865

McCarroll (2018). Remembering from the outside. Oxford University Press. https://doi. org/10.1093/oso/9780190674267.003.0001

Mueller, R. O. \& Hancock, G. R. (2001). Factor analysis and latent structure, confirmatory. In N. J. Smelser \& P. B. Baltes (Eds.), International Encyclopedia of the Social \& Behavioral Sciences (pp. 5239-5244). Elsevier. https://doi.org/10.1016/B0-08-043076-7/00426-5

Oeberst, A., Wachendörfer, M. M., Imhoff, R. \& Blank, H. (2021). Rich false memories of autobiographical events can be reversed. Proceedings of the National Academy of Sciences, 118(13), e2026447118. https://doi.org/10.1073/pnas.2026447118

Otgaar, H., Scoboria, A. \& Mazzoni, G. A. L. (2014). On the existence and implications of nonbelieved memories. Current Directions in Psychological Science, 23(5), 349-354. https://doi.org/10.1177/0963721414542102

Otgaar, H., Bucken, C., Bogaard, G., Wade, K. A., Hopwood, A. R., Scoboria, A. \& Howe, M. L. (2019). Nonbelieved memories in the falsememory archive. Journal of Applied Research in Memory and Cognition, 8(4), 429-438.

Rosenbaum, R. S., Köhler, S., Schacter, D. L., Moscovitch, M., Westmacott, R., Black, S. E. \& Tulving, E. (2005). The case of KC: contributions of a memory-impaired person to memory theory. Neuropsychologia, 43(7), 989-1021. https://doi.org/10.1016/j. neuropsychologia.2004.10.007

Rubin, D. C, Schrauf, R. W. \& Greenberg, D. L. (2003). Belief and recollection of autobiographical memories. Memory \& Cognition, 31, 887-901. https://doi.org/10.3758/BF03196443 
Sacks, O. (2005). On memory. The Threepenny Review. https://www.threepennyreview.com/ samples/sacks_w05.html

Salje, L. \& Geddes, A. (forthcoming). Conscious experience: what's in it for me? In M. García Carpintero \& M. Guillot (Eds.), The Sense of Mineness. Oxford University Press.

Scoboria, A., Boucher, C. \& Mazzoni, G. A. L. (2015). Reasons for withdrawing belief in vivid autobiographical memories. Memory, 23, 545-562. https://doi.org/10.1080/09658211 .2014 .910530

Scoboria, A., Jackson, D. L., Talarico, J., Hanczakowski, M., Wysman, L. \& Mazzoni, G. A. L. (2014). The role of belief in occurrence within autobiographical memory. Journal of Experimental Psychology: General, 143(3), 1242-1258. https://doi.org/10.1037/a0034110

Scoboria, A., Mazzoni, G. A. L., Kirsch, I. \& Relya, M. (2004). Plausibility and belief in autobiographical memory. Applied Cognitive Psychology, 18, 791-807. https://doi. $\operatorname{org} / 10.1002 /$ acp.1062

Scoboria, A., Nash, R. A. \& Mazzoni, G. A. L. (2016). Sub-types of nonbelieved memories reveal differential outcomes of challenges to memories. Memory, 25(7), 876-889. https://doi. org/10.1080/09658211.2016.1203437

Stuss, D. T. \& Guzman, D. A. (1988). Severe remote memory loss with minimal anterograde amnesia: a clinical note. Brain and Cognition, 8(1), 21-30. https://doi.org/10.1016/02782626(88)90036-X

Talland, G. A. (1964). Self-reference:a neglected component in remembering. American Psychologist, 19(5), 351-353. https://doi.org/10.1037/h0039768

Trakas, M. (2019). On epistemic responsibility while remembering the past: the case of individual and historical memories. Les ateliers de l'éthique / The Ethics Forum, 14(2), 240-273. https://doi.org/10.7202/1071139ar

Tulving, E. (1983). Elements of Episodic Memory. Oxford University Press. 